\title{
Bioaccumulation of polychlorinated biphenyls in mullet fish in a former ship dismantling harbour, a contaminated estuary, and nearby coastal fish farms
}

\author{
Chung-Te $\mathrm{Fu}^{\mathrm{a}, \mathrm{b}, *}$, Shian-Chee $\mathrm{Wu}^{\text {a }}$ \\ ${ }^{a}$ Graduate Institute of Environmental Engineering, National Taiwan University, 71 Zhou Shan St. Taipei City 106, Taiwan \\ ${ }^{\mathrm{b}}$ Department of Environmental Engineering, Vanung University, 1 Vanung Rd. Chungli City 325, Taiwan
}

\begin{abstract}
This study investigated the bioaccumulation of polychlorinated biphenyls (PCBs) toward mullet fish (Liza macrolepis) living in former PCB contaminated areas, the Ann-Ping harbour and the Er-Jen estuary, and fish farms located near the above two areas in 2003. The PCB body burdens of collected fish samples are proportional to the contamination level of their locations with the following rank order (greatest to least) from the Er-Jen estuary, the Ann-Ping harbour to the fish farms. Concentration of PCBs of the estuarine mullet has been approximately decreased to one-half of the peak concentration of the 1990s. Although the concentration of PCBs in farmed fish inhabiting near the two contaminated areas was greater than the average of those of fish from local fish markets in Taiwan, no particularly great contamination level was observed in their bodies. Using the less chlorinated PCB fraction (triCB + tetraCB)/total PCBs as the indicator of the origins of PCBs, fish near former contaminated areas had greater body burdens of the more chlorinated PCB congeners, while the farmed fish exhibited a PCB pattern more like that known to originate from air-water exchange with less chlorinated PCBs predominating. Although the PCB contamination has been stopped for a decade, the residual contaminants, supposedly existing in soil and sediments, still contribute to the body burden of fish residing in the estuary and the harbour.
\end{abstract}

(c) 2005 Elsevier Ltd. All rights reserved.

Keywords: PCBs; Er-Jen estuary; Ann-Ping harbour; Fish farm; Liza macrolepis

\section{Introduction}

Ann-Ping was built by the Netherlands colonial occupants as the first economical and political center of Taiwan in 1624. Ann-Ping harbour had been one of the most important trading doors in southern Taiwan for the past three centuries. During the latest century, however, the deposition of silt from upstream erosion clogged the water canals, decreased the loading capacity and finally limited her trading operation. Then, at the early 1980s, ship dismantling industry came into this harbour and soon became

\footnotetext{
${ }^{*}$ Corresponding author. Address: Department of Environmental Engineering, Vanung University, 1 Vanung Rd. Chungli City 325, Taiwan. Tel.: +886 $34515811 \times 705 /+886223629435$; fax: +8863 4622232/+886 2 23629435.

E-mail address: tedfu@msa.vnu.edu.tw (C.-T. Fu).
}

one of the prevalent business in this harbour. Ships were dismantled in this harbour and recovered for steel, electrical devices, and other valuable parts. Some of these devices such as capacitors and transformers were delivered to the nearby Er-Jen estuary for further recovery of valuable metals. The on-site open burning and acid washing operations held for the metal recovery at the esturine region heavily polluted her ecosystem. Additionally, the on-site disassembling of transformers and capacitors in the river shore led to the leakage of transformer oil into the environment and serious contamination of soils, river water, river sediment and even the biota residing in this estuary. A concentration of PCBs as great as $77 \mu \mathrm{g} / \mathrm{g}$ was found in the topsoils of the estuary river shore in early 1990 (Huang et al., 1992), that in the river sediment was still as great as $7.4 \mu \mathrm{g} / \mathrm{g}$ organic in $2003(\mathrm{Fu}$ and $\mathrm{Wu}$, in press), and 
relative great $\mathrm{PCB}$ body burdens, as compared to other locations in Taiwan, were also reported in the biota inhabiting this estuary (Chen et al., 1994; Ling et al., 1995) and nearby coastal farms (Lu et al., 1995).

Nevertheless, without authoritative restriction on fishing in the harbour and the estuary, commercial fishing and sport fishing still prevail in these two regions. Fishes caught in these areas may have the possibility to threaten the health of the consumers for their long-term intake of the contaminated fishes. Furthermore, a number of coastal fish farms located near the harbour and the estuary were suspected exposed to the contamination through air-water exchange and atmospheric deposition due to former larger scale recovering operation (Ling et al., 1995; Lu et al., 1995). Fish in these farms, though, are considered not to contact with the former contaminated sediment directly, still have the potential to accumulate PCBs from water and airborne particles deposited. Until now, these farms are still providing the majority of fish supply for local fish markets.

The predominant species in the concerned area, mullet fish (Liza macrolepis) (Kuo and Shao, 1999), is a benthic feeder, for which sediment detritus comprised $98 \%$ of its dietary source (Horinouchi and Sano, 2000). Therefore, $\mathrm{PCBs}$ retained in the sediments were presumed to be the dominant source of the fish that resided in these two suspected contaminated areas. Alternatively, the fish that inhabited the nearby coastal fish farms without direct contact with the contaminated sediments might be exposed to PCBs through the water rather than the sediment. Thus, concentrations of $\mathrm{PCBs}$ in these fish may exhibit different profiles, and the PCB body burden may also vary significantly according to their life experience.

In the past, most of the studies were focused on the fishes residing in this estuary. There was lacking in understanding on the extent of PCB accumulation and exposure route of fishes that inhabited the harbour and the fish farms. Therefore, the bioaccumulation potential of $\mathrm{PCBs}$ toward to the fishes inhabiting these regions deserves further investigation and detail inspection. By investigating the concentration of PCBs and congener profiles of fish samples from the estuary, the harbour and the fish farm, this study will shed light on the contamination and exposure pathway of PCBs toward the organism that resided in these regions.

\section{Materials and methods}

\subsection{Sample collection}

The mullet was chosen to be the target species for its high accumulation potential as observed in previous studies (Chen et al., 1994; Wang et al., 2000). Nineteen mullet fish samples of the Ann-Ping harbour were collected in May $(n=9)$ and September $2003(n=10)$ from the main sport fishing region near the Billion-Year Fortress, a famous touring attraction and officially certificated first-class

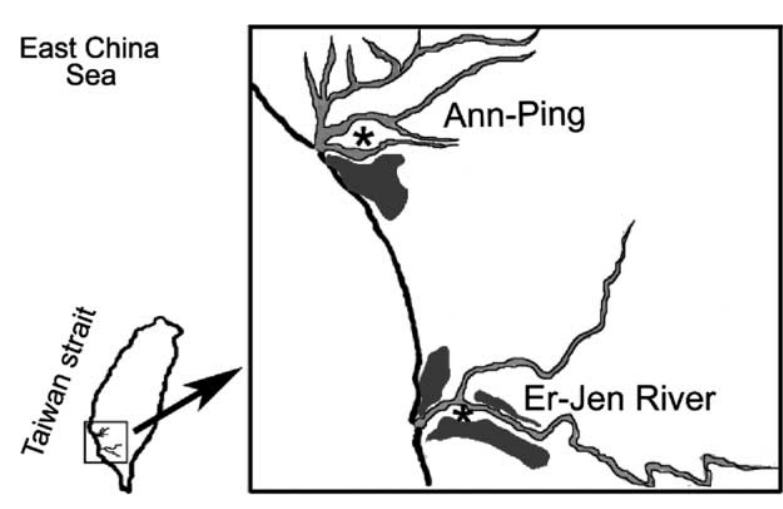

Fig. 1. Locations of the sampling field, mullet fish were collected in the harbour, the Er-Jen estuary and nearby fish farms. * marks the sampling points of the harbour and the estuary, while shade areas represent the locations of fish farms.

heritage (Fig. 1). Fish of the Er-Jen estuary were collected in May $(n=35)$ and September $2003(n=16)$. Eight fish confirmed to be raised in the local fish farm near the ErJen estuary were purchased in September 2003 from a local fish market. Due to local harvest practices for mullet fish, no sample from local fish markets was available in spring. All samples were refrigerated and delivered to the laboratory for further processing.

\subsection{Sample preparation and analyses}

The fillets of fish samples were freeze-dried for $100 \mathrm{~h}$ and crumbled into fine mince. About $5.0 \mathrm{~g}$ of dry mince were transferred into a soxhlet apparatus and extracted with $300 \mathrm{~mL}$ of the mixture of residue grade acetone and $n$-hexane $(1: 1, \mathrm{v} / \mathrm{v})$ in a $70^{\circ} \mathrm{C}$ water bath for $36 \mathrm{~h}$. Extracts were then concentrated to $1 \mathrm{~mL}$ on a rotary evaporator (Büchi) and cleaned by $5 \mathrm{~mL}$ concentrated sulfuric acid (Merck), then back extracted with hexane three times and concentrated to $1 \mathrm{~mL}$ by nitrogen purging. The $1 \mathrm{~mL}$ concentrate then passed through one $30 \mathrm{~cm}$ long pipette $(10 \mathrm{~mm}$ ID) packed with sulfuric acid (Merck) treated silica gel (70230 mesh, for column chromatography, Macherey-Nagel), silver nitrate (J.T. Baker) coated silica gel and florisil (Merck). This extract was finally eluted with $70 \mathrm{~mL} n$-hexane and rotary-evaporated to $1 \mathrm{~mL}$ for $\mathrm{GC}$ analysis. Fish lipid content analyses were performed through weighing after rotary evaporation prior to the purification with concentrated sulfuric acid.

Concentration of PCBs were quantitatively analyzed by a high resolution gas chromatograph (Agilent 6890N) equipped with a ${ }^{63} \mathrm{Ni}$ electron capture detector (ECD) and a $30 \mathrm{~m} \times 0.25 \mathrm{~m} \times 0.25 \mu \mathrm{m}, 5 \%$ phenyl phase fused silica capillary column (RT-5mx, J\&W). The column flow was set at $1 \mathrm{~mL} / \mathrm{min}$ with a linear velocity of $27 \mathrm{~cm} / \mathrm{min}$. The oven temperature program was as following : $80^{\circ} \mathrm{C}$ for $4 \mathrm{~min}$, to $160^{\circ} \mathrm{C}$ at $20^{\circ} \mathrm{C} / \mathrm{min}$, to $265^{\circ} \mathrm{C}$ at $2{ }^{\circ} \mathrm{C} / \mathrm{min}$, to $295^{\circ} \mathrm{C}$ at $25^{\circ} \mathrm{C} / \mathrm{min}$ and held for $5 \mathrm{~min}$. The injector was set at $250^{\circ} \mathrm{C}$ with splitless mode, and the detector was set at $295^{\circ} \mathrm{C}$. A mixture of Aroclor 1242/1254/1260 
(1:1:1) was introduced as a quantification standard (Supelco). Forty-two peaks (IUPAC NO. 18, 16, 28/31, 33, 52, $49,48 / 47,41,70,66 / 95,56,92,101,99,83,97,110,151$, $135,149,118,146,153,105,141,163,138,158,187,183$, $128,185,174,177,171,180,170,201,203,195$ and 194) were identified and summarized as $\sum$ PCB. Decachlorobiphenyl CB209 (Supelco) was spiked into the sample before the extraction as a surrogate of the target compounds. The internal standard of GC performance was 2, 4, 6-trichlorobiphenyl CB30 (Supelco). Only the peaks within proper range $(2 \%)$ of the retention time when compared to the standards were counted for the quantification of PCBs congeners. Every batch (10 samples) was coupled with one blank and one duplicate sample. The PCBs in the blank were less than $2 \mathrm{ng}$ and deviation of duplication ranged within $9-17 \%$. One additional mixed congener standard (CB18, 28, 31, 52, 44, 101, 149, 118, 153, 138, 180 and 194, Supelco) was applied to evaluate the selected congeners' quantities of Aroclor mixture standard, the deviation between these two standards was $15 \pm 7 \%$. The recovery of surrogate CB209 was $78 \pm 7 \%$ of all fish samples. All data were not corrected to the recovery.

\section{Results and discussion}

\subsection{General information of fish samples}

The general information of size, weight and lipid content of the collected samples are shown (Table 1). The average size and weight of the fish raised in the fish farms were larger than the wild ones. The lipid content of these samples deviated significantly within different locations and seasons with the fish from the coastal farms ranked highest, followed by the harbour and the estuary. This could be attributed to the sufficient food supply in fish farms, while the fish grown in natural location were believed to have limited

Table 1

Numbers, sizes, weights and lipid contents of fish samples from three locations in spring and autumn

\begin{tabular}{|c|c|c|c|c|}
\hline \multicolumn{2}{|c|}{ Sample description } & Size, $\mathrm{cm}$ & Weight $^{\mathrm{a}}, \mathrm{g}$ & Lipid $^{\mathrm{b}}, \%$ \\
\hline \multicolumn{5}{|c|}{ Ann-Ping harbour } \\
\hline Spring & Mean $^{c}$ & $18.0 \pm 1.36$ & $68 \pm 15.2$ & $6.2 \pm 3.2$ \\
\hline$(n=9)$ & Range & $17.5-21$ & $51-98$ & $4.3-9.5$ \\
\hline Autumn & Mean & $17.1 \pm 1.2$ & $70.5 \pm 16.8$ & $10.7 \pm 2.0$ \\
\hline$(n=10)$ & Range & $16-19$ & $67-72$ & $8.5-14$ \\
\hline \multicolumn{5}{|c|}{ Er-Jen estuary } \\
\hline Spring & Mean & $17.6 \pm 2.3$ & $65.0 \pm 19.0$ & $4.4 \pm 2.8$ \\
\hline$(n=35)$ & Range & $15-23.5$ & $45-106$ & $1.8-13$ \\
\hline Autumn & Mean & $19.0 \pm 1.0$ & $84.1 \pm 17.0$ & $5.6 \pm 2.7$ \\
\hline$(n=18)$ & Range & $17.3-20.5$ & $74-106$ & $2-10$ \\
\hline \multicolumn{5}{|l|}{ Fish farm } \\
\hline Autumn & Mean & $21.0 \pm 0.9$ & $149.5 \pm 12.0$ & $13.3 \pm 3.0$ \\
\hline$(n=8)$ & Range & $21-23$ & $141-166$ & $9-16$ \\
\hline
\end{tabular}

\footnotetext{
a The weight of the whole fish.

b The lipid contents were based on the fillets.

${ }^{c}$ Mean value is expressed as mean \pm standard deviation.
}

food supply and gain less as comparing with the farmed ones.

\subsection{PCB concentration}

The average wet weight (ww) and lipid adjusted (lpd) concentration of PCBs ( $\sum$ PCB) of the mullet fish sample are given (Fig. 2). Fish collected in the heavily contaminated Er-Jen estuary exhibited the greatest $\sum$ PCB $\left(7.2 \times 10^{2} \pm 1.1 \times 10^{3} \mathrm{ng} / \mathrm{g}\right.$ ww of autumn samples, and $3.4 \times 10^{2} \pm 3.0 \times 10^{2} \mathrm{ng} / \mathrm{g}$ ww of spring samples), followed by those in the harbour $\left(2.2 \times 10^{2} \pm 1.2 \times 10^{2} \mathrm{ng} / \mathrm{g}\right.$ ww of autumn samples, and $69 \pm 19 \mathrm{ng} / \mathrm{g}$ ww of spring samples) and in the fish farm $(22 \pm 3 \mathrm{ng} / \mathrm{g}$ ww $)$. Lipid adjusted $\sum$ PCB exhibited similar result. Two values in autumn as great as $4.2 \times 10^{3} \mathrm{ng} \mathrm{PCB} / \mathrm{g}$ ww $\left(6.0 \times 10^{4} \mathrm{ng} \mathrm{PCB} / \mathrm{g} \mathrm{lpd}\right)$ and $2.5 \times 10^{3} \mathrm{ng} \mathrm{PCB} / \mathrm{g}$ ww $\left(2.5 \times 10^{4} \mathrm{ng} / \mathrm{g}\right.$ lpd $)$ significantly deviated from the autumn average value.

Differences in location were believed to be the dominating factor for the deviation of these samples. The operations of metal recovery lasted for several years and huge amount of PCBs had been discharged into the estuary during that period, while the ship dismantling industry held in
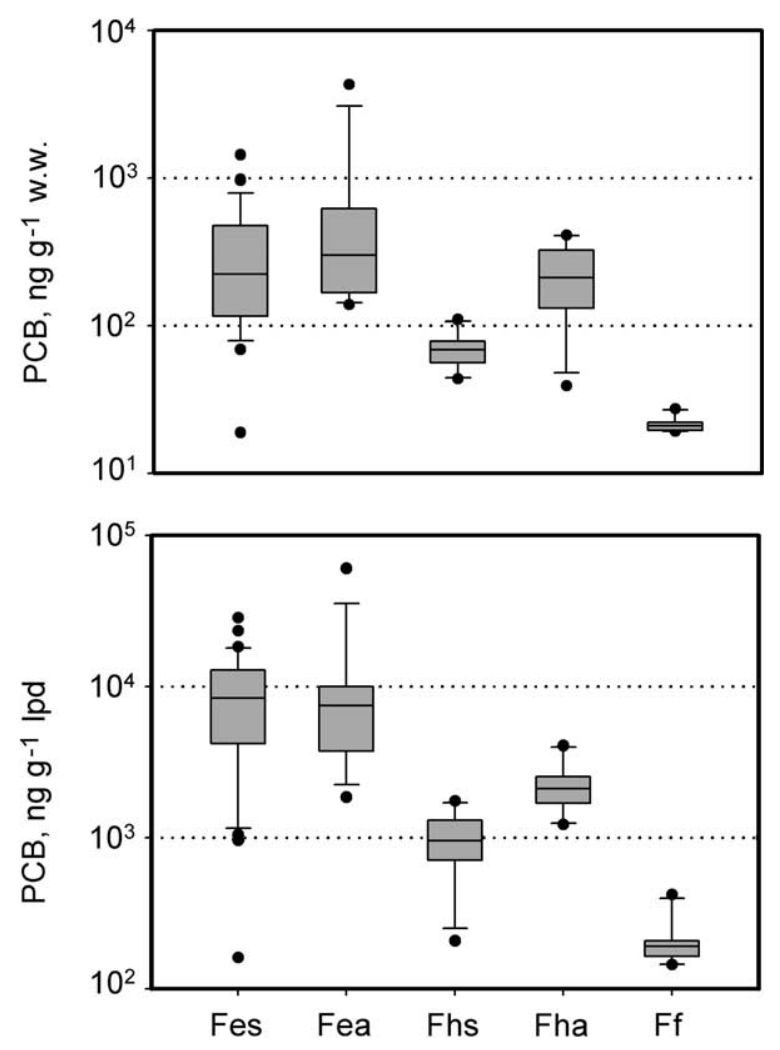

Fig. 2. Box plots of the concentration of PCBs expressed as wet weight base (up) and lipid base (down) show significant deviations $(p<0.0001$, ANOVA) among concerned locations, bottom and top boundary of box represent 25th and 75th percentile, the line within the box marks the median. Whiskers above and below the box indicate the 90th and 10th percentiles. Dots outside the whiskers represent the outliers. Fes: fish samples from estuary in spring; Fea: from estuary in autumn; Fhs: from harbour in spring; Fha: from harbour in autumn; Ff: from fish farm. 
the harbour faded out earlier than the banning of metal recovery in the estuary. It is believed that less amount of PCBs leaked into the harbour than into the estuary. On the other hand, the fish farms that located near the river shore were reconstructed after the banning of metal recovery. Therefore, the concentrations of PCB residues in the sediments of the concerned locations are presumed to be in the following rank order from the estuary, the harbour to the fish farm. Thus the fish inhabiting the estuary had exposed to greater PCB contamination level than the fish in harbour and farms had. The greater concentration in the estuarine mullets than in the farms was the result of residual PCBs sorbed in the suspended solids and sediments of the estuary and harbour, which were originated from former dismantling and recycling processes held in these regions.

The greatest concentration of PCBs in fish ever-found in Taiwan $\left(3.4 \times 10^{3} \pm 4.7 \times 10^{2} \mathrm{ng} / \mathrm{g} \mathrm{dw}\right)$ was observed in mullet fish in the Er-Jen estuary in 1994, and followed by tarpon (Megalops cyprinoides) and tilapia (Oreochromis hybrids) at the same location in the same year (Table 2). The concentration of PCBs of the Er-Jen's tilapia was $1.3 \times 10^{2} \mathrm{ng} / \mathrm{g}$ ww or was approximately equivalent to $5.0 \times 10^{2} \mathrm{ng} / \mathrm{g} \mathrm{dw}$ (Wang et al., 2000), which was already $60 \%$ of the 1994 peak value $\left(8.2 \times 10^{2} \pm 4.5 \times 10^{2} \mathrm{ng} / \mathrm{g}\right.$ $\mathrm{dw})$. It seemed a descending trend of concentration of PCBs in fish in the Er-Jen river after banning the use of
PCBs for near a decade. Similarly, in our study, the average $\sum P C B$ of the mullet fish was $1.9 \times 10^{3} \mathrm{ng} / \mathrm{dw}$, which was only $56 \%$ of the 1994 's observed peak. Both studies reveal that approximately one-half of the environmental source has been eliminated after one decade's attenuation. However, there is still $\sum \mathrm{PCB}$ as great as either $4.2 \times 10^{3} \mathrm{ng}$ $\mathrm{PCB} / \mathrm{g}$ ww or $1.9 \times 10^{4} \mathrm{ng} / \mathrm{g} \mathrm{dw}$ of the fish collected. The concentrations of PCBs in the fishes in the rivers of southern Taiwan are greater than those of northern Taiwan (Table 2), and similar results were found by Lung and coworkers (2003) who investigated the concentrations of PCBs in fishes around the island and found that fishes caught in southern Taiwan possessed greater body burden than the fish from northern Taiwan. This result might be attributed to that majority of manufacturing plants, such as petrochemical, steel mining and paper mill, are located in southern Taiwan. Comparing to other abroad regions, the concentration of PCBs in the Er-Jen estuary is greater than the results previously observed from the river Seine (Chevreuil et al., 1995; Blanchard et al., 1997), San Francisco bay (Fairey et al., 1997) and German bight (Hühnerfuss et al., 1995), but is far below the Housatonic river in which concentrations of PCBs were up to $556 \mathrm{mg} / \mathrm{kg}$ ww in bass (Reiser et al., 2004).

The $\sum \mathrm{PCB}$ of the fish samples from the Ann-Ping harbour in autumn and spring were $2.7 \times 10^{2}$ and $69 \mathrm{ng} / \mathrm{g} \mathrm{ww}$, respectively. In the past, no observation had ever been

Table 2

Concentrations of PCBs of fishes in different locations

\begin{tabular}{|c|c|c|c|c|}
\hline Location & Species & Concentration, ng/g & Reference & Note \\
\hline \multicolumn{5}{|l|}{ Taiwan area } \\
\hline Er-Jen river ${ }^{\mathrm{s}}$ & Liza macrolepis & $3400 \pm 470$ & Chen et al. (1994) & $\mathrm{dw}$ \\
\hline Er-Jen river & Oreochromis hybrids & $825 \pm 451$ & Chen et al. (1994) & $\mathrm{dw}$ \\
\hline Er-Jen river & Megalops cyprinoides & $918 \pm 67$ & Chen et al. (1994) & $\mathrm{dw}$ \\
\hline Er-Jen river & Liza macrolepis & $0-172$ & Hsu (1997) & $\mathrm{dw}$ \\
\hline Keelung river $^{\mathrm{n}}$ & Oreochromis hybrids & $0.1-0.43$ & Hsu (1997) & $\mathrm{dw}$ \\
\hline Keelung river & Oreochromis hybrids & 73 & Liu and Huang (1999) & $\mathrm{dw}$ \\
\hline Tansui river ${ }^{\mathrm{n}}$ & Liza macrolepis & 13 & Huang (1999) & ww \\
\hline Keelung river & Oreochromis hybrids & 17.7 & Wang et al. (2000) & ww \\
\hline Tansui river & Oreochromis hybrids & 13.2 & Wang et al. (2000) & ww \\
\hline Er-Jen river & Oreochromis hybrids & 130 & Wang et al. (2000) & ww \\
\hline Donkang river $^{\mathrm{s}}$ & Oreochromis hybrids & 26.1 & Wang et al. (2000) & ww \\
\hline Average of fish markets & Oreochromis hybrid & 0.18 & Lung et al. (2003) & ww, * \\
\hline \multicolumn{5}{|l|}{ Foreign area } \\
\hline Housatonic river & Bass & 556000 & Reiser et al. (2004) & ww \\
\hline Seine river & Rutilus rutilus & $1300-16000$ & Chevreuil et al. (1995) & $\mathrm{dw}$ \\
\hline \multirow[t]{2}{*}{ Seine river } & Rutilus rutilus & $1847-3600$ (spring) & Blanchard et al. (1997) & $\mathrm{dw}$ \\
\hline & & 2083-7500 (autumn) & & \\
\hline \multirow[t]{3}{*}{ San Fran. Bay } & White croaker & 340 & Fairey et al. (1997) & ww \\
\hline & Halibut & 55 & & \\
\hline & Shiner surfperch & 160 & & \\
\hline Lake Tanganyika & Seven species & $35-166$ & Manirakiza et al. (2002) & lpd \\
\hline Fish farm & Dicentrarchus labrax & $155-294$ & Antunes and Gil (2004) & lpd \\
\hline
\end{tabular}

ww: Concentration of PCBs is represented as $\mathrm{ng} / \mathrm{g}$ wet weight.

$\mathrm{dw}$ : Concentration of PCBs is represented as $\mathrm{ng} / \mathrm{g}$ dry weight.

lpd: Concentration of PCBs is represented as $\mathrm{ng} / \mathrm{g}$ lipid.

$\mathrm{s}, \mathrm{n}$ : $\mathrm{s}$ denotes that the river locates in southern Taiwan, while $\mathrm{n}$ denotes for northern Taiwan.

*: Selected congeners (PCB 28/31, 52, 66, 77, 105/153, 118, 126, 128, 138, 156, 157, 167, 169, 170, 180, and 189). 
reported on the contamination level and exposure sources. Although the ship dismantling industry has faded out for more than a decade, it is believed that the residues are still retained in this region and accumulated in the body of biota inhabiting there.

The $\sum$ PCB was $22 \pm 3 \mathrm{ng} / \mathrm{g}$ ww or $1.7 \times 10^{2} \pm 23 \mathrm{ng} / \mathrm{g}$ lpd in the farmed fish, which was far less than those of the samples from the other two contaminated areas, and was in the same magnitude of the samples from other slightly contaminated local rivers as shown (Table 2). However, compared with the farmed fish reported locally and abroad (Table 2) including the tilapia samples $(0.18 \mathrm{ng} / \mathrm{g}$ ww) in Taiwan (Lung et al., 2003), the pooled fresh water fish samples $(7.8 \mathrm{ng} / \mathrm{g} \mathrm{ww})$ collected from different supermarkets in the US (Schecter et al., 1997), the PCB level is slightly greater and is in the range as the farmed bass in Portugal, $1.5 \times 10^{2}-2.9 \times 10^{2} \mathrm{ng} / \mathrm{g}$ lpd (Antunes and Gil, 2004). In general, fish lived in the farms that near the two contaminated areas did not show particularly high concentration of PCBs than other studies. However, the average $\sum$ PCB of the studied fish in the concerned fish farms is still greater than those of the fish samples from other fish markets in Taiwan. Although the concentration of PCBs in farmed mullets is less than the dietary standard, the tendency of PCB accumulation in these fish farms deserves prolonged monitoring.

\subsection{Congener profile}

A total of 42 peaks, from trichlorobiphenyls to octachlorobiphenyls, were identified as shown (Fig. 3). In respect of the main congeners of these profiles, samples from the harbour and the estuary were different from that of the farmed ones. The main congeners of the former two profiles were CB138, CB180, CB 153 and CB118, in which hexachlorobiphenyls and pentachlorobiphenyls comprised the major portion of $\sum \mathrm{PCB}$; while those of the farmed fish were CB52, CB118 and CB138, and tetrachlorobiphenyls and hexachlorobiphenyls were the most abundant congeners of the farmed samples.

The ratios of individual congeners to $\mathrm{CB} 153$ varied significantly ( $p<0.0001$, ANOVA) for all the selected congeners in these locations (Fig. 4). The greater ratio of CB138/ CB153 and CB180/CB153 of the estuarine and harbour's

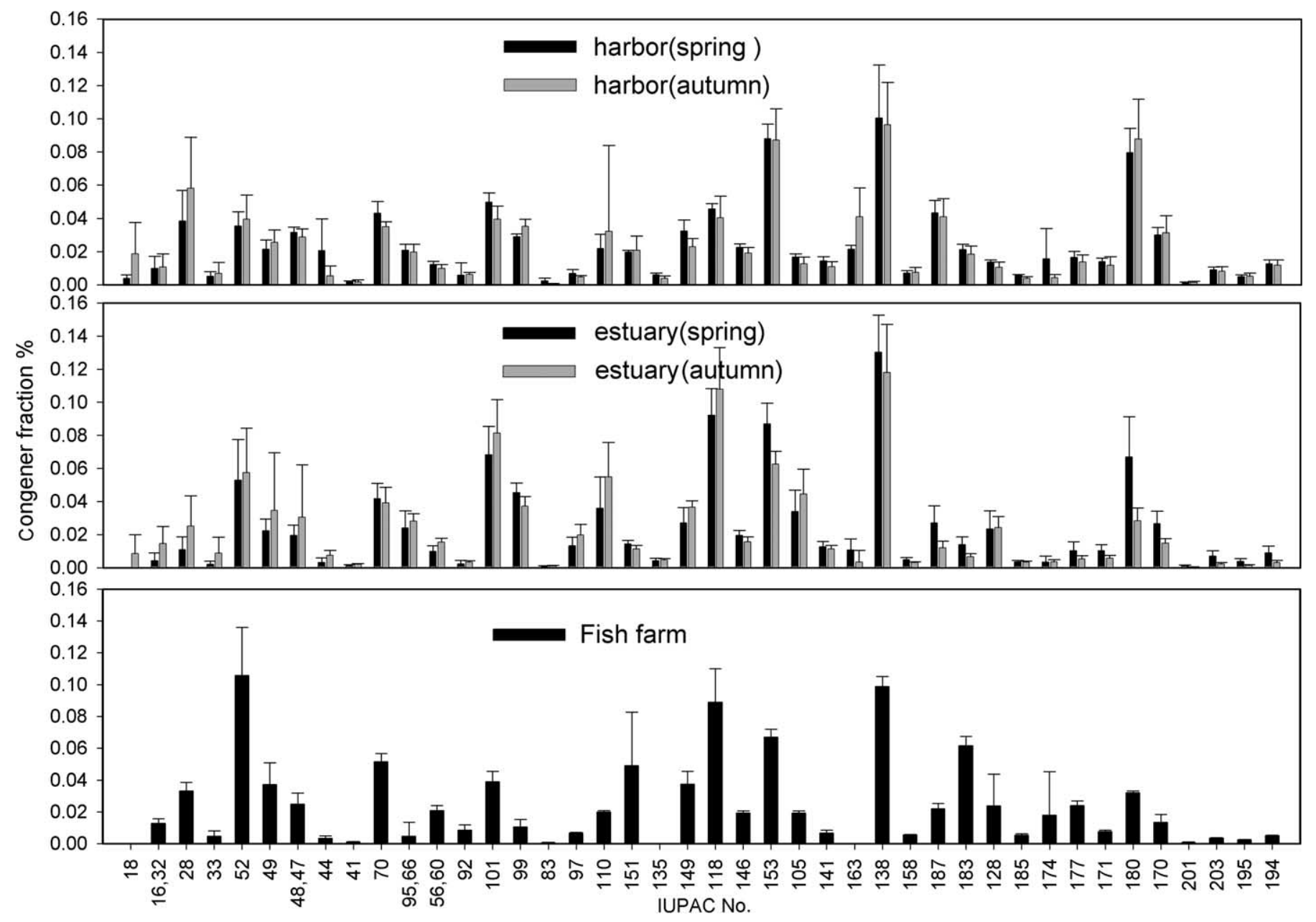

Fig. 3. Percentage (mean \pm standard deviation) of individual PCB congeners in fish in the Ann-Ping harbour (above), the Er-Jen estuary (middle) and fish farms (below) in spring (black bar) and autumn (gray bar), respectively. 

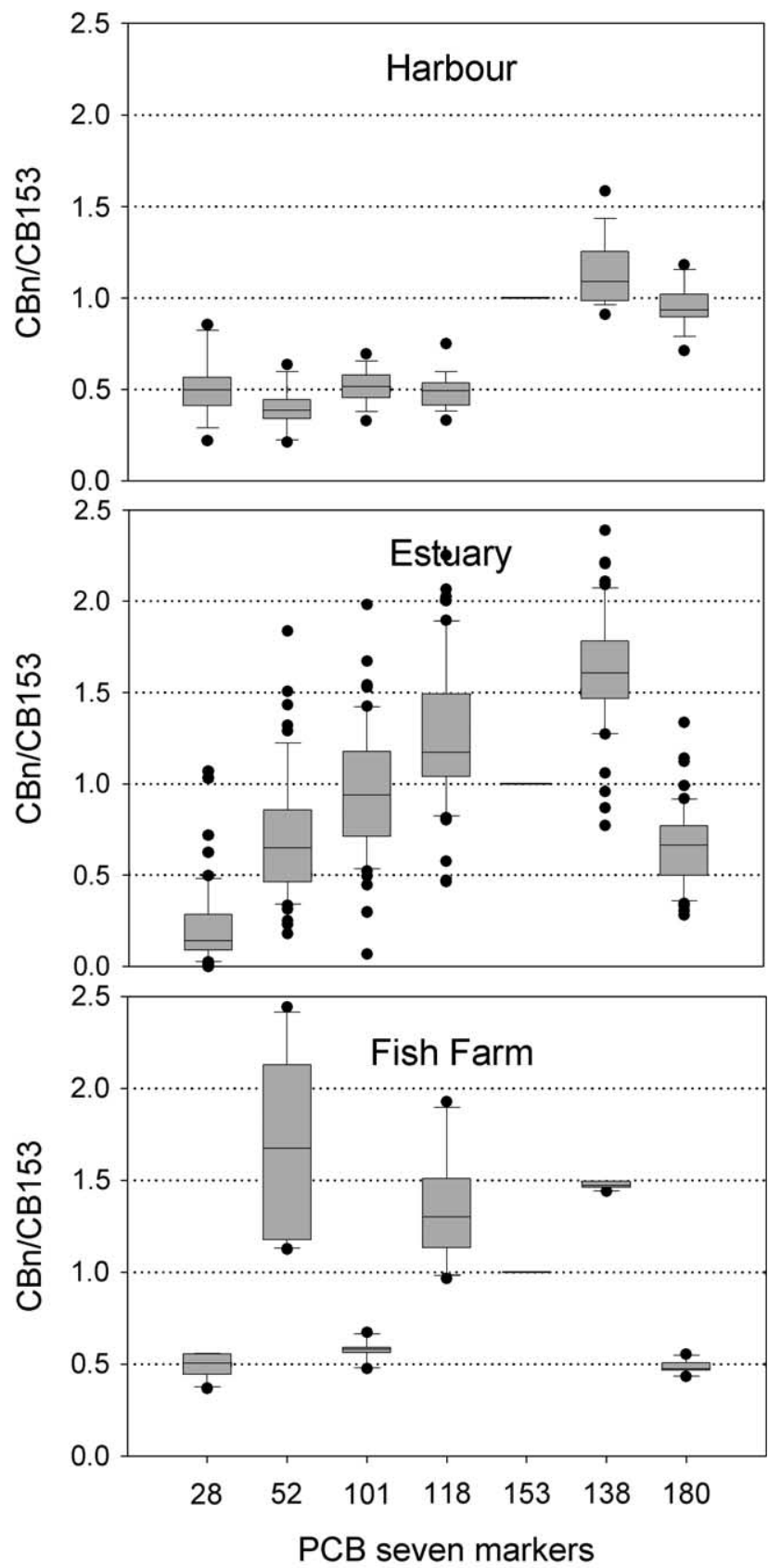

Fig. 4. Box plots of the ratio of $\mathrm{PCB}$ seven markers to $\mathrm{CB} 153$ in the concerned locations.

fish, as shown in Fig. 4, indicated that CB 138 and CB180 were the dominant congeners. However, the dominant congener of the farmed fish was CB52, which is similar to what was found in the fish samples such as milkfish, white pomfret and hailtail that purchased from local fish markets of Taiwan (Lung et al., 2003). Additionally, in Lung's study, the ratio of $\mathrm{CB} 52 / \mathrm{CB} 153$ of the hailtail samples from southern coast of Taiwan was even much greater than our observation.

The relatively great variability observed with the fractions of individual congeners to $\sum$ PCB (Fig. 3) also imply that the contamination sources are likely different among locations and even seasonally. The homologue distributions of light PCBs (triCB + tetraCB), medium PCBs (pentaCB + hexaCB) and heavy PCBs (heptaCB + octaCB) in the concerned areas are displayed in Fig. 5. Medium PCBs are the main homologue of all the samples and comprise near $50 \%$ of the total content, while light and heavy PCBs share the other half. Fish samples from the Er-Jen estuary possessed the highest contamination level and exhibited the highest fraction of medium PCBs with lowest fraction of light PCBs, while the farmed fish exhibited lowest fraction of medium PCBs and highest fraction of light PCBs. The homologue distribution of the harbour samples was intermediate compared to the other two locations. Such deviation was supposedly attributed to the contamination level and congener distribution of locations where these fish samples came from.

Ashley and Baker (1999) have shown that sediments near emission source contained heavy-chlorinated PCBs, while sediments far away contaminated areas exhibited light-chlorinated PCBs. The $\sum \mathrm{PCB}$ of the estuarine surface sediments was in the range of $7.0 \times 10^{2}$ to $7.4 \times 10^{3} \mathrm{ng} / \mathrm{g}$ organic ( $\mathrm{Fu}$ and $\mathrm{Wu}$, in press). Therefore, if surface sediments were assumed as the dietary source of benthic feeders such as our target fish, mullet, then fish samples from the contaminated estuary and harbour should have carried more chlorinated PCBs in their body, and fish raised in the farms should have exhibited more light-chlorinated PCBs than the other two contaminated areas. In this study, the chlorination characteristics of studied samples in different locations varied and followed the sequence of historic contamination events. If the degree of the aging of PCBs is inversely correlated to the light PCB fraction, then the light PCB fraction that ranks from the least (the harbour), the intermediate (the estuary) to the greatest (farms) does reflect the sequence of events in the past.

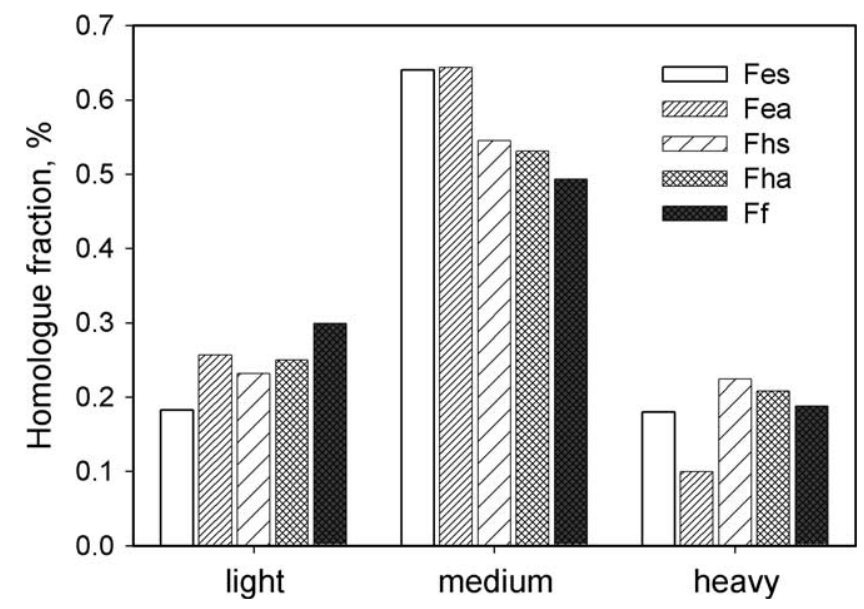

Fig. 5. PCB homologue fractions (mean \pm standard deviation) of fish in different locations; chlorination degree is expressed as light PCBs (trichlorobiphenyls + tetrachlorobiphenyls), medium PCBs (pentachlorobiphenyls + hexachlorobiphenyls) and heavy PCBs (heptachlorobiphenyls + octachlorobiphenyls). 
On the other hand, the estuary and the harbour have long been recognized as the contaminated areas of PCBs. Fish residing in these regions would unavoidably contact with the contaminated water and sediments. PCBs, retained in the sediments and dissolved in the water, were sorbed and accumulated in the fish body through gill exchange and dietary uptake. However, since light PCBs comprised major fraction of total concentration of PCBs in water, the exposure route of PCBs for farmed fish was most probably from the air-water exchange. The deviation of the congener profiles and homologue distributions also reflect either the local-contaminant origin or the long-range transport origin.

One might argue that the differences of contamination level and congener profile in these locations are not attributed to the differences in locations but rather as the physiological behaviors of fish. Some reasons can explain this question. First, the studied fish are belonged to the same species and lived in nearby regions that minor differences of physiological behavior are anticipated. Secondly, the studied regions are either the completely closed fish farms or the semi-closed harbour and estuary. Thus the mullets were proposed to live in confined regions that their feeding habitat varied insignificantly as comparing to an open system. Finally, the other possible differences due to different season are also evaluated in this study. Therefore, the difference of location seems to be the main factor that governs the deviation of contamination level and profile of PCBs in the fish.

Principal component analysis, a multivariate statistical method, was applied to the congener profiles of these samples from different locations in spring or in autumn. The PCA result of case distribution, as shown in Fig. 6, indicates that fish from different locations exhibit distinct patterns, and fish from the estuary show seasonal variation. No seasonal deviation can be observed in harbour's fish,

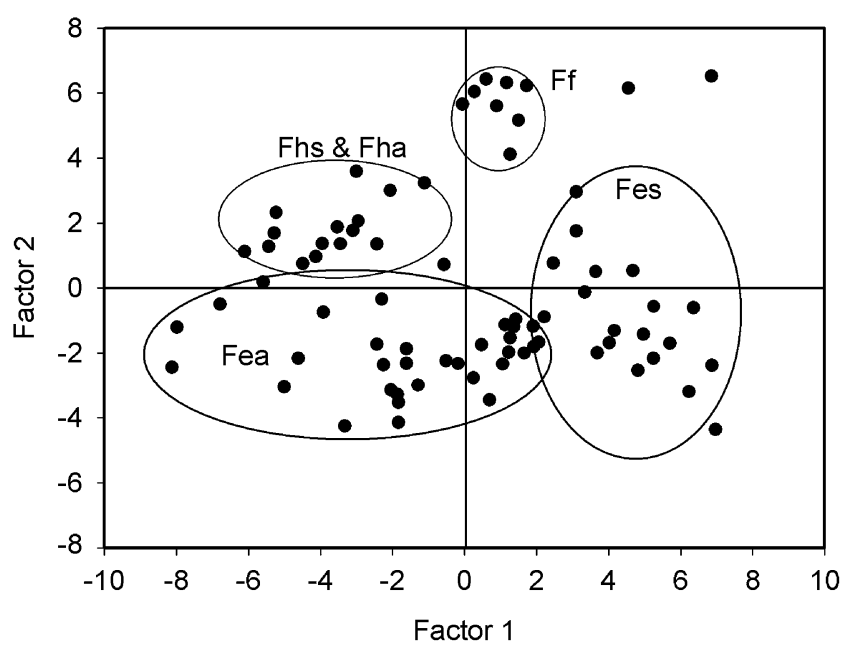

Fig. 6. Principal component analysis of fish from different locations in spring and autumn, which indicates that fish from different locations exhibit distinct pattern, and fish from the estuary show seasonal variation. which means that the sources of PCB contamination in the harbour are independent of season. On the contrary, the distinct seasonal pattern of PCBs in the estuarine fish suggests that the sources of contamination in the estuary vary. The reasons of and mechanisms causing the seasonal variation are not well understood. Further investigation on the seasonal change of sediment in the harbour and fish farms will be of great help to elucidate such mechanisms.

\section{References}

Antunes, P., Gil, O., 2004. PCB and DDT contamination in cultivated and wild sea bass from Ria de Aveiro, Portugal. Chemosphere 54, 1503 1507.

Ashley, J.T.F., Baker, J.E., 1999. Hydrophobic organic contaminants in surficial sediment of Baltimore harbour: inventories and sources. Environ. Toxicol. Chem. 18, 838-849.

Blanchard, M., Teil, M.J., Carru, A.M., Chesterikoff, A., Chevreuil, M., 1997. Organochlorine distribution and mono-orthosubstituted PCB pattern in the roach (Rutilus rutilus) from the River Seine. Water Res. 31, 1455-1461.

Chen, W.F., Wang, H.C., Liu, C.Z., 1994. Fish species and PCB concentration in the Er-Jen river. Ann. Rep. Natl. Inst. Environ. Anal. Taiwan ROC 2, 305-318 (in Chinese).

Chevreuil, M., Carru, A.M., Chesterikoff, A., Boet, P., Tales, E., 1995. Contamination of fish from different areas of the river Seine (France) by organic (PCB and pesticides) and metallic (Cd, $\mathrm{Cr}, \mathrm{Cu}, \mathrm{Fe}, \mathrm{Mn}, \mathrm{Pb}$ and $\mathrm{Zn)}$ micropollutants. Sci. Tot. Environ. 162, 31-42.

Fairey, R., Taberski, K., Lamerdin, S., Johnson, E., Clark, R.P., Downing, J.W., 1997. Organochlorines and other environmental contaminants in muscle tissues of sportfish collected from San Francisco Bay. Mar. Pollut. Bullet. 34, 1058-1071.

Fu, C.-T., Wu, S.C., Seasonal variation of the distribution of PCBs in sediments and biota in a PCB-contaminated estuary. Chemosphere, in press.

Horinouchi, M., Sano, M., 2000. Food habits of fishes in a Zostera marina bed at Aburatsubo, central Japan. Ichthyol. Res. 47, 163-173.

Hsu, D.P., 1997. The analyses of main PCB congeners that bioaccumulated in fish tissue in Taiwan. Ann. Rep. Natl. Inst. Environ. Anal. Taiwan ROC 5, 253-260 (in Chinese).

Huang, H.Z., 1999. Analyses of PCB content in fishes of the Tansui river. Ann. Rep. Natl. Inst. Environ. Anal. Taiwan ROC 7, 257-264 (in Chinese).

Huang, C.W., Miyata, H., Lu, J.R., 1992. Levels of PCBS, PCDDS and PCDFS in soil samples from incineration sites for metal reclamation in Taiwan. Chemosphere 24, 1669-1676.

Hühnerfuss, H., Pfaffenber, B., Gehrcke, B., 1995. Stereochemical effects of PCBs in the Marine environment-Seasonal variation of coplanar and atropisomeric PCBs in blue mussels of the German bight. Mar. Pollut. Bull. 30, 332-340.

Kuo, S.R., Shao, K.T., 1999. Species composition of fish in the coastal zones of the Tsengwen Estuary, with descriptions of five new records from Taiwan. Zool. Stud. 38, 391-404.

Ling, Y.C., Soong, D.K., Lee, M.K., 1995. PCDD/DFs and coplanar PCBs in sediment and fish samples from the Er-Jen river in Taiwan. Chemosphere 31, 2863-2872.

Liu, C.Z., Huang, H.Z., 1999. Analysis of PCBs content in fishes of Taiwan area with GC/MS. Ann Rep. Natl. Inst. Environ. Anal., Taiwan ROC 7, 229-236 (in Chinese).

Lu, J.R., Miyata, H., Huang, C.W., Tsai, H.T., Sheng, V.Z., Nakao, T., Mase, Y., Aozasa, O., Ohta, S., 1995. Contamination levels of PCDDs, PCDFs and non-orthochlorine substituted coplanar PCBs in milkfish and crab from culture pond and coastal area near open-air incineration sites for metal reclamation in Wan Li, Taiwan, Republic of China. Chemosphere 31, 2959-2970. 
Lung, S.C., Chen, C.F., Hu, S.C., Bau, Y.P., 2003. Exposure of Taiwan residents to polychlorinated biphenyl congeners from farmed, oceancaught, and imported fish. Environ. Sci. Technol. 37, 4579-4585.

Manirakiza, P., Covaci, A., Nizigiymana, L., Ntakimazi, G., Schepens, P., 2002. Persistent chlorinated pesticides and polychlorinated biphenyls in selected fish species from Lake Tanganyika, Burundi, Africa. Environ. Pollut. 117, 447-455.

Reiser, D.W., Greenberg, E.S., Helser, T.E., Branton, M., Jenkins, K.D., 2004. In situ reproduction, abundance, and growth of young-of-year and adult largemouth bass in a population exposed to polychlorinated biphenyls. Environ. Toxicol. Chem. 23, 1762-1773.

Schecter, A., Cramer, P., Boggess, K., Stanley, J., Olson, J.R., 1997. Levels of dioxins, dibenzofurans, PCB and DDE congeners in pooled food samples collected in 1995 at supermarkets across the United States. Chemosphere 34, 1437-1447.

Wang, C.H., Huang, H.Z., Hong, W.C., 2000. Analysis of PCBs in the fishes in Taiwan river. Ann. Rep. Natl. Inst. Environ. Anal. Taiwan ROC 8, 115-130 (in Chinese). 